\title{
Clonal micropropagation of essential oil rose cultivars and breeding samples at long-term subcultivation in vitro
}

\author{
$N A$ Yegorova $^{1, *}$, and $I V$ Stavtzeva $^{1}$ \\ ${ }^{1}$ Research Institute of Agriculture of Crimea, 295493, Kievskaya str.150, Simferopol, Russian \\ Federation
}

\begin{abstract}
The development of explants of 12 cultivars and breeding samples of essential oil rose (obtained with the participation of Rosa damascena Mill., $R$. gallica L., $R$. alba L.) during long-term micropropagation was investigated. At the second multiplication stage 5 subcultures were carried out. Increase of the studied morphometric parameters of explants to $3-4^{\text {th }}$ subcultures was established. In some genotypes, the maximum multiplication index was in the third subculture (cultivars 'Raduga', 'Zolushka', 'Lada', 'Krymskaya Krasnaya', 'Lany', 'Vesna' and samples N37-24, M215), while in others (cultivar 'Kazanlykskaya' and samples N138, G2168, N37-2) - in the fourth. The largest increase of the multiplication index in $3-4^{\text {th }}$ subcultures compared to the first (3.0-4.8 times) was found in the cultivars 'Lada', 'Lany', 'Raduga', 'Krymskaya Krasnaya' and sample N37-24. In the fifth subculture the multiplication index decreased. However, in most cultivars and breeding samples it was higher than in the first subculture. The best morphogenetic potential was noted for cultivar 'Raduga' and samples G2168, N37-2, in which the multiplication index reached 14.2, 14.4 and 11.8 , respectively. The minimal ability to propagation in vitro was in samples M215 and N138 - their multiplication index did not exceed 1.14.0 .
\end{abstract}

\section{Introduction}

Essential oil rose is one of the best known aromatic plants worldwide. It is mainly cultivated in the Mediterranean and the Middle East countries - Bulgaria, Turkey, France, Morocco, Iran, India, etc. The genus Rosa (family Rosaceae Juss.) includes hundreds of species and thousands of cultivars. But only a few species of this genus are used to produce essential oils - R. damascena Mill., $R$. gallica Linn., R. moschata Herrm., R. centifolia Linn., $R$. bourboniana Desportes., $R$. chinensis Jacq., $R$. alba Linn. [1]. One of the most important essential oil Rosa species is $R$. damascena, which belongs to the Damask group of roses and is known for its strong fragrance [2].

\footnotetext{
* Corresponding author: yegorova.na@mail.ru
} 
Interest in this plant is associated with a wide range of its use. There are four main products which are obtained from essential oil rose - essential oil, concrete, absolute and rose water. Rose oil is widely used as a base component of many high-quality perfumes and cosmetics - perfumes, eau de toilette, shampoos, creams and other skin care products. Rosa has many culinary uses as a flavor additive or as an antioxidant and antibacterial agent in food industry. The modern investigations on $R$. damascena have confirmed the antibacterial, antiviral, anti-inflammatory, anticancer, antidepressant, analgesic and anticonvulsant activities [3]. In medicine rose is applied for the treatment of diseases of mouth and throat, cardiovascular system, cholecystitis, gastritis, ulcers and many others.

In Russia, essential oil rose is currently grown in the southern regions, mainly in the Crimea. Most of the high-yielding and adapted to the conditions of this region cultivars were obtained by hybridization with the participation of species of $R$. damascena, $R$. gallica, $R$. alba [4]. To improve the breeding of roses, it is necessary to develop biotechnological methods, in particular, clonal micropropagation, which has many advantages compared to traditional methods. Propagation in vitro allows accelerating the reproduction of valuable breeding samples, hybrids, new cultivars, as well as receiving virus-free planting material. This method is also the basis for creating collections in vitro.

There are far less works devoted to research on clonal micropropagation for essential oil roses than for ornamental ones. These publications mostly covered issues of $R$. damascena propagation in vitro [2, 5-8]. As explants when introduced into an aseptic culture, axillary or apical buds and meristems [5, 8-10], stem segments with a node [7, 9, 11-12] were usually used. There is evidence of the use of direct shoot regeneration from leaf, stem and petiole for $R$. damascena micropropagation [1]. Protocol for in vitro propagation using induction of shoot buds from leaf explants of in vitro-raised shoots of $R$. damascena cultivar 'Jwala' was developed [2]. A. Ginova et al. reported about induction of indirect organogenesis from rose callus [2]. However, to obtain a genetically stable planting material, meristems or buds are most frequently used as explants, from which the probability of obtaining somaclonal variants is less.

The information on micropropagation of essential oil rose presented in various literature sources almost always focuses on the optimization of the culture medium composition for the different stages of propagation in vitro. The compositions of culture media recommended by different authors for the multiplication stage are very diverse $[1-2,9,11$, 13]. As cytokinin, many authors recommend the introduction of 6-benzylaminopurine (BAP) into the culture medium composition [6, 9-11, 14]. Thus, some studies have shown the efficiency of relatively high concentrations of this growth regulator $-3.0 \mathrm{mg} / 1$ [11-12], $4.0 \mathrm{mg} / 1$ [9], $6.0 \mathrm{mg} / \mathrm{l}$ [7]. Often, for better shoot proliferation, BAP was used in combination with indole-3-butyric acid (IBA) [15] or $\alpha$-naphthaleneacetic acid (NAA) [16]. Different studies have shown the efficiency of thidiazuron [1, 17] or the combined use of cytokinin, gibberellic acid $\left(\mathrm{GA}_{3}\right)$ and auxin ( $\alpha$-naphthaleneacetic acid, indole-3-acetic acid) $[1-2,6]$. B. Allahverdi Mamaghani et al. [5] recorded the highest level of shoot multiplication rate at a combination of $5 \mathrm{mg} / \mathrm{l}$ BAP and $0.1 \mathrm{mg} / \mathrm{l}$ thidiazuron. For three genotypes (Kashan damask rose, Yasooj aromatic rose and their hybrid), the best shoot formation from shoot tip explants was achieved on MS medium with BAP $(0.5 \mathrm{mg} / \mathrm{l}), \mathrm{N}^{6}-2-$ isopentenyl adenine $(0.5 \mathrm{mg} / \mathrm{l})$ and IBA $(0.1 \mathrm{mg} / \mathrm{l})$ [8]. At the same time, M. Salekjalali [13] for $R$. damascena revealed the effectiveness of introducing into the medium not only BAP and NAA, but also phloroglucinol, which enhanced the multiplication rates in vitro. $\mathrm{H}$. M. Noodezh et al. found that an increase in the content of $\mathrm{NH}_{4} \mathrm{NO}_{3}, \mathrm{CaCl}_{2}$ and $\mathrm{FeSO}_{4}$ in the culture medium contributed to a 5-10-fold increase in the number of shoots per explant in $R$. damascena [9].

In addition to the influence of the culture medium composition, in some studies the effect of other exogenous or endogenous factors on the development of rose explants during 
micropropagation was analyzed. An important role in this process of the genotype [5-6, 8, 15], explant type [1-2], explant size [7], explant isolation season [5, 10] was noted for scented roses. So, in the work of Allahverdi Mamaghani et al. it was noted that appropriate seasons for introduction in vitro were summer and autumn [5]. For different regions of the Crimea, the best time for introducing explants into the culture was February-March [10] or August [18]. Some papers have noted the influence of light source on rose micropropagation [1]. A. Kumar and L.M.S. Palni [3] showed enhanced growth and better shoot proliferation in shoot cultures grown under photosynthetically active radiation as compared with cultures maintained under cool fluorescent lights.

To increase the efficiency of fragrant rose propagation or to overcome the problems that arise during this process, some authors used different conditions of cultivation. There is evidence of the successful use of the liquid medium for micropropagation $[1,6,9]$. In order to regenerate $R$. damascena on a large scale, an efficient propagation system has been established using transverse thin cell layer culture [16]. A. Ginova and V. Kondakova [14] for $R$. damascena Mill. f. trigintipetala Dieck. propagation used a temporary immersion bioreactor system to overcome the problem with top necrosis of microshoots. A. Bosh et al. [7] also showed that a temporary immersion system was significantly better than solid ore liquid media for shoot multiplication.

However, the data presented in the literature are sometimes ambiguous and many questions of the clonal micropropagation of roses have not been studied enough. So, in several works the influence of the genotype is noted, however, only 2-3 cultivars or samples were studied [5-6, 8, 15]. In other articles, there is no exact indication of the studied sample or cultivar [9, 13-14]. Many studies do not specify the number of subcultures carried out at the micropropagation stage. Several publications present rather contradictory data on the effect of the number of subcultures on the development of explants and the formation of shoots of essential oil roses [1, 11, 17]. However, this is an important question, since the effectiveness of in vitro micropropagation and storage techniques depends on this, as well as the ability to obtain the required number of propagated plants.

The aim of the work was to study the influence of long-term subcultivation on explants development in vitro and micropropagation of essential oil rose cultivars and breeding samples.

\section{Materials and methods}

The objects of our investigations were essential oil rose cultivars ('Raduga', 'Vesna', 'Krymskaya Krasnaya', 'Zolushka', 'Lany', 'Lada', 'Kazanlykskaya') and breeding samples (N138, G2168, M215, N37-2, N37-24), obtained with participation of species Rosa damascena Mill., R. gallica L. and R. alba L. [4]. Plants were grown in the collection plot of Research Institute of Agriculture of Crimea. To introduce in vitro, meristems with two leaf primordia $(0.3-0.5 \mathrm{~mm})$ were used as primary explants. They were excised from the vegetative buds under a binocular microscope MSP-1 (LOMO, Russia). Sterilization of plant material was carried out using $70^{\circ}$ ethanol (1 min), and then 50\% "Bradofen" solution (Florin, Hungary) for 10 minutes. For micropropagation, stem segments with one node isolated after microcutting from test tube shoots were used as explants.

The explants were cultured on modified Murashige and Skoog (MS) culture medium with $1.0 \mathrm{mg} / 1 \mathrm{BAP}$ and $0.1 \mathrm{mg} / \mathrm{l} \mathrm{GA}_{3}$ (Sigma, USA), previously optimized for clonal micropropagation of essential oil rose [18]. Culture medium was solidified with agar $7 \mathrm{~g} / \mathrm{L}$. The cultivation of meristems was carried out in test tubes with $10 \mathrm{ml}$ of medium. On multiplication stage, the cultures were grown in 200-ml glass jars containing $40 \mathrm{ml}$ of medium with five explants per jar. Jars were closed with aluminium foil. Explants were 
kept under standard culture conditions at $24-26^{\circ} \mathrm{C}, 70 \%$ of relative air humidity, under $16-\mathrm{h}$ photoperiod with light intensity 2000-3000 lux.

The explants were cultivated for 30 days, after which analysis of morphometric parameters of rose explants was performed. Then microcuttings of the shoots were carried out. For morphometric analysis, length and number of shoots (per explant), number of leaves (per explant), nodes number (per shoot), frequency of multiple shoot formation (\%) were determined. The multiplication index was calculated as the number of microcuttings that can be obtained during one subculture. For this, the number of shoots formed on an explant was multiplied by the number of nodes on a shoot.

Experiments were carried out in three replications; 15 explants were analyzed at each variant. The data were processed using the Microsoft Office software package (Excel 2010). Significance of differences was assessed by the Student criterion at $P \leq 0.05$. The tables and the graphs show average values and their standard errors.

\section{Results}

In an aseptic culture in vitro on the MS medium with $1.0 \mathrm{mg} / \mathrm{l} \mathrm{BAP}$ and $0.1 \mathrm{mg} / \mathrm{l} \mathrm{GA}$ meristems of 7 cultivars and 5 breeding samples were introduced. The analysis of cultures revealed a relatively slow development of meristems for all genotypes. An increase in the size of explants and the formation of the first leaf blade were observed two weeks later. The number of viable developing explants was minimal in N138 (78.6\%), and in the remaining genotypes it was $92.7-100.0 \%$. After one month of cultivation, the length of the shoots reached $6.6-8.5 \mathrm{~mm}$ (Table 1.). At the same time, small rosettes of leaves were formed representing microshoots with shortened internodes. The number of leaves was maximum for G2168 and N37-2 (2.0 and 2.2 pcs per explant). The studied genotypes (except N138) developed several small shoots and buds. Frequency of multiple shoot formation varied depending on the cultivar and breeding sample. The smallest ability to form several shoots was typical for cultivar 'Vesna' (18.8\%); the maximum frequency of multiple shoot formation was observed in N37-2 (72.4\%). The average number of shoots per explant ranged from $1.0(\mathrm{~N} 138)$ to $2.5(\mathrm{~N} 37-2)$ pcs.

Table 1. Development of meristems of different essential oil rose cultivars and breeding samples under introduction in vitro.

\begin{tabular}{|c|c|c|c|c|}
\hline Cultivar, breeding sample & $\begin{array}{c}\text { Frequency of } \\
\text { multiple shoot } \\
\text { formation (\%) }\end{array}$ & $\begin{array}{c}\text { Shoots } \\
\text { number per } \\
\text { explant (pcs) }\end{array}$ & $\begin{array}{c}\text { Shoot length } \\
(\mathrm{mm})\end{array}$ & $\begin{array}{c}\text { Leaves } \\
\text { number per } \\
\text { explant } \\
(\mathrm{pcs})\end{array}$ \\
\hline 'Raduga' & $68.9 \pm 5.8$ & $2.0 \pm 0.1$ & $7.9 \pm 0.3$ & $1.9 \pm 0.2$ \\
\hline 'Vesna' & $18.8 \pm 2.2$ & $1.2 \pm 0.1$ & $7.7 \pm 0.5$ & $1.5 \pm 0.1$ \\
\hline 'Krymskaya Krasnaya' & $56.5 \pm 4.0$ & $1.7 \pm 0,1$ & $6.6 \pm 0.4$ & $1.4 \pm 0.1$ \\
\hline 'Zolushka' & $42.9 \pm 4.5$ & $1.5 \pm 0,1$ & $8.5 \pm 0.7$ & $1.6 \pm 0.1$ \\
\hline 'Lany' & $34.6 \pm 2.7$ & $1.2 \pm 0.1$ & $7.6 \pm 0.2$ & $1.5 \pm 0.1$ \\
\hline 'Lada' & $39.5 \pm 2.9$ & $1.2 \pm 0.1$ & $7.3 \pm 0.3$ & $1.4 \pm 0.1$ \\
\hline 'Kazanlykskaya' & $43.8 \pm 3.1$ & $1.5 \pm 0.1$ & $7.0 \pm 0.3$ & $1.5 \pm 0.1$ \\
\hline N138 & 0 & 1.0 & $7.7 \pm 0.5$ & $1.4 \pm 0.1$ \\
\hline G2168 & $64.3 \pm 5.4$ & $2.1 \pm 0.1$ & $6.8 \pm 0.4$ & $2.0 \pm 0.2$ \\
\hline M215 & $30.0 \pm 2.5$ & $1.4 \pm 0.1$ & $7.2 \pm 0.3$ & $1.2 \pm 0.2$ \\
\hline $\mathrm{N} 37-2$ & $72.4 \pm 6.5$ & $2.5 \pm 0.2$ & $7.8 \pm 0.4$ & $2.2 \pm 0.1$ \\
\hline $\mathrm{N} 37-24$ & $46.3 \pm 4.0$ & $1.2 \pm 0.1$ & $7.2 \pm 0.3$ & $1.2 \pm 0.2$ \\
\hline
\end{tabular}


For further propagation at the second multiplication stage, stem segments with a node were used as explants. They were transplanted every month to MS culture medium with 1.0 $\mathrm{mg} / \mathrm{l} \mathrm{BAP}$ and $0.1 \mathrm{mg} / \mathrm{l} \mathrm{GA}_{3}$. The analysis of morphometric parameters of 12 rose genotypes was carried out during 5 subcultures. The results of a study of explants development in the first and $3-5^{\text {th }}$ subcultures are presented in Table 2 . When explants were cultured for 1 month, 1-2 microshoots were developed from axillary buds. Several adventitious buds or shoots were also formed frequently. Since the developing adventitious shoots were small, the average shoot length was relatively small, too. Many microshoots, especially in the first subculture, had shortened internodes and micro rosettes of leaves. In the first subculture shoot length vary from 6.6 ('Kazanlykskaya') to $9.8 \mathrm{~mm}$ (N37-2). Further subculture led to formation longer shoots with normal internodes. The average microshoot length in 3-5 subcultures varied from 8.5 to $16.0 \mathrm{~mm}$ depending on the genotype and the number of subcultures. The smallest shoots were developed in sample M215 (8.5-8.8 mm); the maximum average shoot sizes (up to 14.1-16.0 mm) were noted in cultivars 'Lada' and 'Raduga' and samples N37-2, N37-24, G2168. The results in Table 2 show that most of the studied genotypes demonstrated high potential for multiplication. The percentages of the multiplicated explants vary from 11.8 to $91.5 \%$ in the first subculture and from 48.5 to $100 \%$ in the third. In the first subculture active formation of additional microshoots was observed. On average, from 1.1 to 4.2 shoots per explant (depending on genotype) were formed. By the third passage, the number of shoots increased (1.5-5.8 pcs per explant), and in the fifth - decreased to 1.3-4.0 pcs per explant. The minimum frequency of multiple shoot formation was observed in the samples M215 and N138 - in the first subculture did not exceed $29.3 \%$, and in a fifth $-41.7 \%$. These samples developed, on average, no more than 1.5-1.8 shoots per explant. The biggest average number of shoots from explant was induced in the first subculture in the cultivar 'Raduga' (4.0 pcs) and sample N37-2 (4.2 pcs). By the third passage, the number of shoots increased in the cultivar 'Raduga' up to 5.8 pcs per explants and in the sample N37-2 up to 5.0 pcs per explants. In 4-5 subcultures this parameter decreased in all studied cultivars and breeding samples. 
Table 2. Influence of subcultures number and genotype on the development of explants during the second stage of essential oil rose micropropagation in vitro.

\begin{tabular}{|c|c|c|c|c|c|}
\hline $\begin{array}{l}\text { Number of } \\
\text { subcultures }\end{array}$ & $\begin{array}{c}\text { Cultivar, breeding } \\
\text { sample }\end{array}$ & $\begin{array}{c}\text { Shoots number } \\
\text { per explant } \\
\text { (pcs) }\end{array}$ & $\begin{array}{l}\text { Shoot length } \\
\qquad(\mathrm{mm})\end{array}$ & $\begin{array}{l}\text { Nodes number } \\
\text { per shoot (pcs) }\end{array}$ & $\begin{array}{l}\text { Frequency of } \\
\text { multiple shoot } \\
\text { formation (\%) }\end{array}$ \\
\hline \multirow{12}{*}{1} & 'Raduga' & $4.0 \pm 0.4$ & $8.0 \pm 0.3$ & $1.1 \pm 0.1$ & $85.7 \pm 7.5$ \\
\hline & 'Vesna' & $2.8 \pm 0.2$ & $9.6 \pm 0.4$ & $1.3 \pm 0.1$ & $72.4 \pm 6.2$ \\
\hline & 'Krymskaya Krasnaya' & $1.9 \pm 0.2$ & $7.2 \pm 0.4$ & $1.1 \pm 0.1$ & $60.0 \pm 5.2$ \\
\hline & 'Zolushka' & $2.0 \pm 0.2$ & $9.6 \pm 0.5$ & $1.2 \pm 0.1$ & $76.3 \pm 6.5$ \\
\hline & 'Lany' & $1.6 \pm 0.2$ & $9.1 \pm 0.4$ & $1.2 \pm 0.1$ & $37.3 \pm 2.2$ \\
\hline & 'Lada' & $1.8 \pm 0.2$ & $8.5 \pm 0.4$ & $1.2 \pm 0.1$ & $38.9 \pm 2.5$ \\
\hline & 'Kazanlykskaya' & $2.3 \pm 0.2$ & $6.6 \pm 0.3$ & $1.1 \pm 0.1$ & $68.2 \pm 5.4$ \\
\hline & N138 & $1.4 \pm 0.1$ & $8.0 \pm 0.4$ & 1.0 & $29.3 \pm 2.8$ \\
\hline & G2168 & $2.7 \pm 0.3$ & $8.5 \pm 0.4$ & $1.2 \pm 0.1$ & $72.7 \pm 6.1$ \\
\hline & M215 & $1.1 \pm 0.1$ & $6.8 \pm 0.4$ & 1.0 & $11.8 \pm 0.8$ \\
\hline & $\mathrm{N} 37-2$ & $4.2 \pm 0.3$ & $9.8 \pm 0.5$ & $1.3 \pm 0.1$ & $91.5 \pm 8.2$ \\
\hline & $\mathrm{N} 37-24$ & $3.2 \pm 0.3$ & $8.9 \pm 0.4$ & $1.2 \pm 0.1$ & $70.4 \pm 6.2$ \\
\hline \multirow{12}{*}{3} & 'Raduga' & $5.8 \pm 0.5$ & $15.8 \pm 0.5$ & $2.4 \pm 0.1$ & $92.8 \pm 7.8$ \\
\hline & 'Vesna' & $3.4 \pm 0.3$ & $12.9 \pm 1.0$ & $2.0 \pm 0.2$ & $72.4 \pm 7.5$ \\
\hline & 'Krymskaya Krasnaya' & $3.2 \pm 0.3$ & $12.5 \pm 0.7$ & $2.0 \pm 0.2$ & $91.7 \pm 7.8$ \\
\hline & 'Zolushka' & $3.2 \pm 0.3$ & $12.6 \pm 0.6$ & $2.1 \pm 0.1$ & $81.8 \pm 7.2$ \\
\hline & 'Lany' & $3.1 \pm 0.5$ & $13.7 \pm 0.6$ & $2.1 \pm 0.1$ & $82.8 \pm 6.8$ \\
\hline & 'Lada' & $4.2 \pm 1.2$ & $16.0 \pm 1.2$ & $2.5 \pm 0.2$ & $70.8 \pm 5.4$ \\
\hline & 'Kazanlykskaya' & $3.1 \pm 0.3$ & $10.6 \pm 0.5$ & $1.5 \pm 0.1$ & $90.5 \pm 8.5$ \\
\hline & $\mathrm{N} 138$ & $1.8 \pm 0.2$ & $11.1 \pm 0.6$ & $1.8 \pm 0.2$ & $66.2 \pm 4.2$ \\
\hline & G2168 & $2.1 \pm 0.2$ & $13.2 \pm 1.1$ & $2.0 \pm 0.2$ & $53.8 \pm 4.3$ \\
\hline & M215 & $1.5 \pm 0.1$ & $8.5 \pm 0.4$ & $1.2 \pm 0.1$ & $48.5 \pm 3.5$ \\
\hline & $\mathrm{N} 37-2$ & $5.0 \pm 0.4$ & $13.2 \pm 0.7$ & $2.0 \pm 0.2$ & 100.0 \\
\hline & N37-24 & $5.3 \pm 0.4$ & $14.1 \pm 0.8$ & $2.2 \pm 0.2$ & $85.8 \pm 7.6$ \\
\hline \multirow{12}{*}{4} & 'Raduga' & $3.4 \pm 0.3$ & $13.1 \pm 0.7$ & $2.6 \pm 0.2$ & $94.2 \pm 7.1$ \\
\hline & 'Vesna' & $3.2 \pm 0.3$ & $12.8 \pm 0.9$ & $2.1 \pm 0.2$ & $78.5 \pm 7.1$ \\
\hline & 'Krymskaya Krasnaya' & $3.0 \pm 0.3$ & $12.2 \pm 1.0$ & $2.0 \pm 0.2$ & $91.7 \pm 7.5$ \\
\hline & 'Zolushka' & $2.4 \pm 0.2$ & $10.6 \pm 0.7$ & $1.3 \pm 0.1$ & $68.5 \pm 6.2$ \\
\hline & 'Lany' & $3.0 \pm 0.3$ & $12.6 \pm 0.4$ & $2.0 \pm 0.1$ & $79.8 \pm 5.1$ \\
\hline & 'Lada' & $3.1 \pm 0.3$ & $12.4 \pm 0.5$ & $2.5 \pm 0.2$ & $90.0 \pm 8.4$ \\
\hline & 'Kazanlykskaya' & $3.2 \pm 0.3$ & $10.3 \pm 0.3$ & $1.6 \pm 0.1$ & $83.3 \pm 7.1$ \\
\hline & N138 & $1.9 \pm 0.2$ & $11.7 \pm 0.7$ & $2.1 \pm 0.2$ & $54.5 \pm 4.9$ \\
\hline & G2168 & $2.6 \pm 0.3$ & $11.3 \pm 0.6$ & $1.8 \pm 0.1$ & $66.7 \pm 5.3$ \\
\hline & M215 & $1.3 \pm 0.1$ & $8.8 \pm 0.4$ & $1.1 \pm 0.1$ & $28.2 \pm 2.1$ \\
\hline & N37-2 & $5.3 \pm 0.4$ & $14.1 \pm 0.9$ & $2.7 \pm 0.2$ & $95.3 \pm 9.2$ \\
\hline & $\mathrm{N} 37-24$ & $3.3 \pm 0.3$ & $13.5 \pm 0.8$ & $2.6 \pm 0.2$ & $77.2 \pm 7.0$ \\
\hline \multirow{12}{*}{5} & 'Raduga' & $2.3 \pm 0.2$ & $14.5 \pm 0.8$ & $2.9 \pm 0.3$ & $76.5 \pm 5.6$ \\
\hline & 'Vesna' & $2.0 \pm 0.3$ & $11.3 \pm 0.7$ & $2.1 \pm 0.2$ & $60.5 \pm 5.6$ \\
\hline & 'Krymskaya Krasnaya' & $2.6 \pm 0.3$ & $11.4 \pm 0.7$ & $1.9 \pm 0.2$ & $78.6 \pm 7.2$ \\
\hline & 'Zolushka' & $2.5 \pm 0.2$ & $10.9 \pm 0.7$ & $1.6 \pm 0.1$ & $67.5 \pm 5.9$ \\
\hline & 'Lany' & $2.4 \pm 0.3$ & $12.0 \pm 0.6$ & $2.2 \pm 0.2$ & $75.0 \pm 5.6$ \\
\hline & 'Lada' & $2.1 \pm 0.2$ & $12.2 \pm 0.8$ & $2.2 \pm 0.2$ & $60.9 \pm 5.5$ \\
\hline & 'Kazanlykskaya' & $2.9 \pm 0.3$ & $11.9 \pm 0.5$ & $1.7 \pm 0.1$ & $79.3 \pm 6.6$ \\
\hline & N138 & $1.7 \pm 0.2$ & $12.3 \pm 0.8$ & $1.8 \pm 0.2$ & $41.7 \pm 3.1$ \\
\hline & G2168 & $1.8 \pm 0.2$ & $14.3 \pm 0.8$ & $2.5 \pm 0.2$ & $59.5 \pm 4.3$ \\
\hline & M215 & $1.3 \pm 0.1$ & $8.9 \pm 0.4$ & $1.1 \pm 0.1$ & $19.5 \pm 1.4$ \\
\hline & $\mathrm{N} 37-2$ & $4.0 \pm 0.4$ & $12.9 \pm 0.7$ & $2.5 \pm 0.2$ & $82.1 \pm 7.7$ \\
\hline & $\mathrm{N} 37-24$ & $2.8 \pm 0.3$ & $11.2 \pm 0.5$ & $2.0 \pm 0.2$ & $78.4 \pm 8.1$ \\
\hline
\end{tabular}


Figure presents data on the change in the multiplication index in 12 genotypes of essential oil rose for 5 consecutive subcultures. The results show that this parameter, as the most important for assessing the propagation efficiency, changed depending on subcultures number and genotype. In the first passage, the multiplication index ranged from 1.1 to 5.6 and was maximum at N37-2. Then a gradual increase of this parameter to $3-4^{\text {th }}$ subcultures was observed. In the third subculture multiplication index ranged from 1.8 to 14.2 , and in the fourth - from 1.4 to 14.4. In the fifth passage in most cultivars and breeding samples multiplication index decreased. In some genotypes ('Vesna', M215, G2168, N37-24), the multiplication index in the fifth subculture did not significantly differ from that in the firs. However, for other genotypes the multiplication index in the fifth subculture was significantly higher than in the first. For example, in the sample N37-2, multiplication index in the first subculture was 4.0 and in the fifth -10.0 .

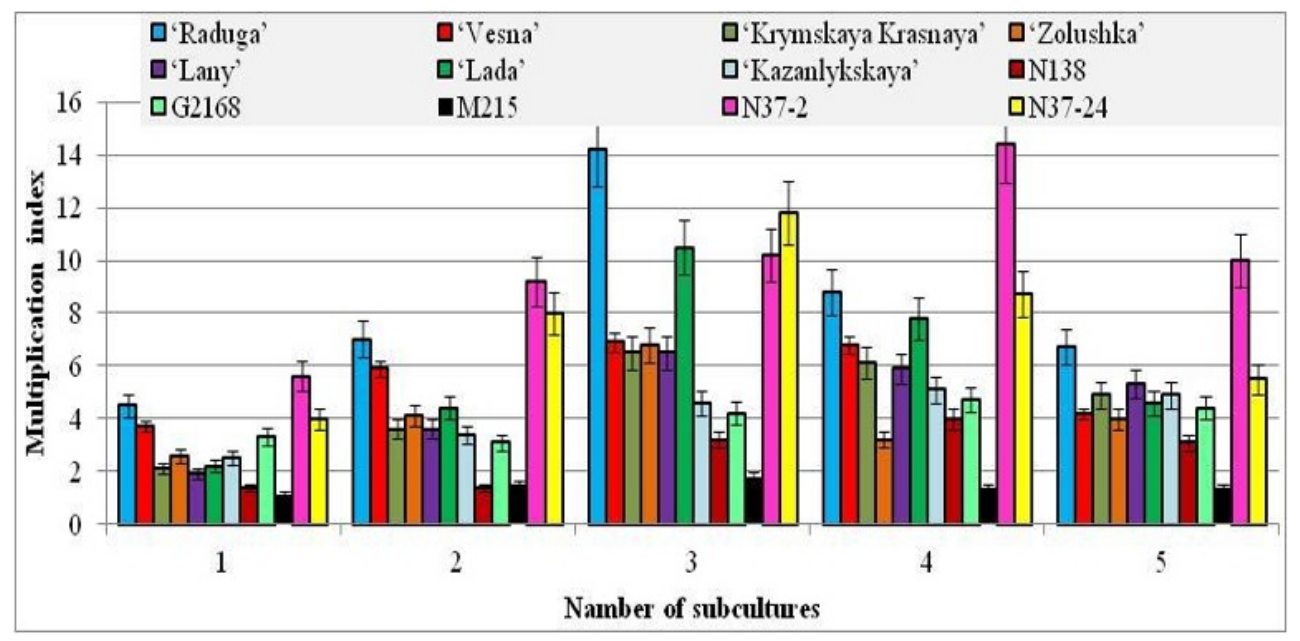

Fig. 1. Influence of subcultures number and genotype on the multiplication index during essential oil rose micropropagation in vitro.

\section{Discussion}

Development of in vitro propagation methods for rapid multiplication of rose cultivars and valuable genotypes (hybrids, mutants, collection samples, obtained in tissue culture regenerants, etc.) is of great importance. A major objective of the present investigation was to study the influence of long-term subcultivation on the micropropagation of essential oil rose cultivars and breeding samples. This question, despite the available publications on the development of essential oil rose in vitro propagation methods, is very poorly studied. However, analysis of the explants development over several subcultures is very important for the creation of effective biotechnologies, since it allows one to find out how long plants can be propagated in vitro without losing their quality. For the practical use of these methods in breeding programs, it is necessary to conduct such studies for a wide range of genotypes grown in a certain region. In our work rose cultivars ('Raduga', 'Vesna', 'Krymskaya Krasnaya', 'Zolushka', 'Lany', 'Lada', 'Kazanlykskaya') and samples (N138, G2168, M215, N37-2, N37-24), used in the breeding process, were studied. At the first stage of initiation of culture, a significant influence of the genotype on the ability to propagation was noted. Frequency of multiple shoot formation and shoots number were maximum for breeding sample N37-2 and 'Raduga' cultivar, which formed 2.5 and 2.0 shoots per explant, respectively. During sample N138 cultivation, very weak development 
of meristems and the absence of additional buds were noted. The remaining morphometric parameters varied slightly in the studied genotypes.

The formation of several shoots at the stage of explant introduction in vitro was noted in many works devoted to the micropropagation of essential oil roses [2, 8-10, 12]. However, some authors noted that explants exude dark colored compounds into the culture medium (phenols, pigments) that are released from the cut ends of the explants [14]. This can cause browning of tissue and medium, which is often connected with poor culture establishment and reduced regeneration ability. The media enriched with activated charcoal, various antioxidants - ascorbic or citric acid, polyvinylpyrrolidone or other substances are often employed to nullify this effect [2]. Frequent subculture, incubation in shaking liquid culture, reduced culture temperature have also been used to deal with this problem [2]. For the genotypes of essential oil roses that we studied, there was no significant negative effect of phenolic compounds. Darkening of explants was observed only in isolated cases. The amount of viable developing meristems was usually over $90-95 \%$.

At the second stage of micropropagation (multiplication stage) not only the forming of small shoots were used for rose propagation, but also microcutting of the shoots with normal internodes was carried out. Some shoots (especially in the $3-4^{\text {th }}$ subcultures) reached 30-40 mm and had 3-5 nodes, so it was advisable to carry out their cuttings. Such single-node stem segments were transferred to a fresh medium. This allowed us to get more explants for propagation and increase the multiplication index. For all cultivars and breeding samples, multiple shoot formation was detected. In the first subculture, the average number of shoots ranged from 1.1 to 4.2 pcs per explant, and to the third increased up 1.5-5.8 pcs per explant. In most genotypes the average number of shoots in 34 subcultures was more than 3.0 pcs per explant, and the 'Raduga', N37-2 and N37-24 had more than 5.0 pcs per explant.

Our data on the number of proliferating shoots during micropropagation of rose varieties and samples are comparable with the results of other researchers. When studying in vitro propagation of three cultivars of $R$. damascena and $R$. gallica, formation from 2.5 to 4.2 shoots per explant was reported [15]. S. Mirzaei et al. at micropropagation of Kashan damask rose, Yasooj aromatic rose and their hybrid received up to 3.4-3.9 shoots per explant depending on genotype [8]. During multiplication in vitro of different $R$. damascena cultivars and samples it was reported obtaining 4.4-6.0 [13], 3.7-4.0 [11], 2.93.8 [12], 5.9 [5] shoots per explant. Z. Jabbarzadeh and M. Khosh-Khui [11] revealed the development of 1.6-7.5 shoots depending on the number of subcultures and the composition of the culture medium. The largest shoots number per explant was obtained from a temporary immersion system (12.3 pcs) [7], or using transverse thin cell layer culture (22.3 pcs) [16].

In our study, we found that in almost all genotypes, the studied morphometric parameters gradually increased to $3-4^{\text {th }}$ subcultures and then decreased with prolonged micropropagation. So, in cultivars 'Lany', 'Lada', 'Raduga', 'Zolushka', 'Krymskaya Krasnaya' and sample N37-24 the number of shoots in the third passage increased by 1.52.3 times compared with the first. During $2-4^{\text {th }}$ subcultures, a slight increase in shoot length and, accordingly, the number of nodes was also observed. This made it possible to obtain more explants during microcutting for further propagation. All this led to an increase of multiplication index in almost all genotypes in $3-4^{\text {th }}$ subcultures, which was significantly higher than in the first one. In the third subculture, the maximal multiplication index was in cultivars 'Raduga', 'Zolushka', 'Lada', 'Krymskaya Krasnaya', 'Lany', 'Vesna' and samples N37-24, M215. At the same time, in cultivar 'Kazanlykskaya' and samples N138, G2168, N37-2 the maximal multiplication index was noted in the fourth subculture. The largest increase of the multiplication index in $3-4^{\text {th }}$ subcultures compared to the first subculture was found in the cultivars 'Lada' (4.8 times), 'Lany' (3.4 times), 'Raduga' (3.2 
times), 'Krymskaya Krasnaya' (3.1 times) and sample N37-24 (3.0 times). For several samples (G2168 and M215), this increase was small (1.4-1.6 times). During subsequent cultivation (in the fifth passage) the multiplication index decreased. However, in most cultivars and breeding samples it was higher than in the first subculture. This was mainly due to the longer shoot length and the number of nodes, which made it possible to increase the efficiency of microcutting.

There are only a few reports on the effect of the number of subcultures on the micropropagation of essential oil roses. Z. Jabbarzadeh and M. Khosh-Khui [11] subcultured shoots of $R$. damascena four times on MS medium containing 2.5-3.0 mg/l BAP and $0.1 \mathrm{mg} / 1 \mathrm{IBA}$. Among the multiplication stages, the first subculture resulted in the highest proliferation rate. In the first subculture 7.46 proliferated shoots was detected, while in the fourth it was only 1.63. In R. moschata the highest proliferation was obtained in the first subculture, but in the second one there were fewer shoots [1]. At the same time, A. Kumar et al. [17] showed the possibility of successful propagation of $R$. damascena during 8-12 subcultures on a medium containing BAP, after which the shoots attained the capacity to grow and proliferate on a medium free from plant growth regulators. For decorative garden rose (Rosa hybrida cvs. 'Cri Cri', 'Pariser Charme', 'First Red'), the frequency of shoot multiplication was the best up to the $6^{\text {th }}-7^{\text {th }}$ subculture and thereafter it declined [19].

We revealed an increase of multiplication index to $3-5^{\text {th }}$ subcultures during in vitro propagation for some other essential oil plants. The experiments with micropropagation of lavender in 9 subcultures showed that the number of shoots increased in all five studied cultivars up to the third subculture and decreased thereafter [20]. During the micropropagation of five mint cultivars and breeding samples during six subcultures, it was found that the multiplication index increased in $3-5^{\text {th }}$ passages, reaching $12.1-48.7$ depending on the genotype and duration of cultivation [21]. When studying the effect of cultivation duration on propagation of Origanum vulgare in vitro, 13 passages were conducted. The maximum number of shoots ( 54.8 pcs per explant) and the multiplication index (74.1) were obtained in the fifth subculture. With further subcultures, the multiplication index decreased [22]. For three cultivars of Melissa officinalis, the maximum value of the studied morphometric parameters and the multiplication index (up to 12.017.6) also were noted in the $3-5^{\text {th }}$ subcultures [22].

Other works also show an increase in the proliferative ability of in vitro cultures to a specific passage. At a continuous multiplication of Gerbera jamesonii, the multiplication rate of most of the 17 cultivars began to increase starting from the $2-3^{\text {rd }}$ subcultures $(3.8$ $4.0)$; reached its maximum in the $4^{\text {th }}$ to $6^{\text {th }}(9.8-10.5)$ subcultures; thereafter started to decline [23]. In the same work, it was shown that in Philodendron tuxlanum the maximum number of shoots per explant was in $4-5^{\text {th }}$ subcultures, $6^{\text {th }}$ and $7^{\text {th }}$ subcultures led to a decrease in the multiplication rate. Multiple shoot formation of Glycyrrhiza glabra was increased from the first (2.2 shoots per explant) to the fourth subculture (6.6 shoots per explant) [24]. G.R.A. Mohamed et al. when developing a protocol for micropropagation of Vaccinium corymbosum showed that the fourth subculture gave the best results for multiplication [25]. However, after the fifth passage, hyperhydrated shoots appeared.

Such an increase of proliferative ability to $3-4^{\text {th }}$ subculture revealed in our study for essential oil roses (and also shown for a number of other plant species) may be due to the optimal combination of the level of endogenous and exogenous (in the nutrient medium) plant growth regulators during this period. A further decrease in the multiplication index, apparently, is associated with a change in the hormonal state of cultured tissues, leading to gradual physiological aging of cultures. Therefore, in the future, it is promising to conduct a comparative analysis of the content of endogenous phytohormones in cultivated rose microshoots of different subcultures. 
However, for some plant species, such an increase of multiplication index to a specific subculture was not found. Repeated subculture of the nodes of Mahonia leschenaultii through at least 10 passages enabled consistent production of 6-7 shoots per explant without loss of vigour, growth and morphological abnormalities [26]. In vitro shoots of vegetative rootstocks cherry, plum and pear were subcultured for 10 passages. Shoot formation capacity decreased over repeated subculturing in all genotypes [27]. Such a decrease may, however, be due to the lack of optimal cultivation conditions or culture medium.

In our study, when culturing rose explants during 5 passages, green microshoots and leaves without morphological anomalies were developed. Only a few cases of the appearance of hyper-hydrated shoots or yellowing of leaves were noted. At the same time, A. Ginova and V. Kondakova [14] reported that during subcultures chlorosis and then necrosis of leaves and apex were appeared. The appearance of yellow leaves, shoot tip necrosis, or abnormal shoots during the rose micropropagation in vitro was noted by a number of authors $[2,5-6]$.

It should be noted that in our study a significant influence of the genotype on the efficiency of micropropagation of essential oil rose was revealed. The maximum proliferative ability of explants at the stage of initiation of culture was noted for cultivar 'Raduga' and samples G2168, N37-2, and the minimum - for M215. With prolonged cultivation (on the multiplication stage), the best morphogenetic potential was shown by cultivar 'Raduga' and samples N37-2, N37-24. By the third passage, they developed more than 5.0 shoots per explant, and the multiplication index reached 14.2, 14.4, and 11.8, respectively. Most of the studied rose genotypes were propagated quite effectively under the conditions used by us. In $1-2^{\text {nd }}$ passages, a low multiplication index was noted only in sample N138 and cultivars 'Lany', 'Krymskaya Krasnaya'. However, with further subcultures, their multiplication index increased significantly, which indicated the need for such samples to carry out several microcuttings for obtaining the required number of microplants. Minimum capacity for propagation showed sample M215; adventitious shoots almost did not develop from explants. Its multiplication index was 1.1-1.8, depending on the number of subcultures. Such different cultivars and samples in vitro reaction may be due to not only a low genetically determined ability to reproduce but also to an unsuitable culture medium. Therefore, for the successful propagation of these samples, it is, probably, necessary to carry out further optimization of the medium composition. In some studies of the species, cultivars and samples of essential oil rose, a significant influence of the genotype on the efficiency of micropropagation in vitro was also established $[1,5-6,10$, 15].

\section{Conclusions}

Thus, the peculiarities of explants development of 7 cultivars and 5 breeding samples of essential oil rose at the first and second stages of micropropagation in vitro were investigated. In the meristem culture of the studied genotypes (except sample N138), multiple shoot formation was observed with a frequency of $18.8-72.4 \%$. At the second multiplication stage 5 subcultures were carried out, during which an average of 1.1-5.8 shoots per explant were formed, depending on the genotype and passage. Increase of the studied morphometric parameters of explants to $3-4^{\text {th }}$ subcultures was established. At the same time, in some genotypes the maximum multiplication index was in the third subculture (cultivars 'Raduga', 'Zolushka', 'Lada', 'Krymskaya Krasnaya', 'Lany', 'Vesna' and samples N37-24, M215), while in others (cultivar 'Kazanlykskaya' and samples N138, G2168, N37-2) - in the fourth. The largest increase of the multiplication index in $3-4^{\text {th }}$ subcultures compared to the first one was found in the cultivars 'Lada' (4.8 
times), 'Lany' (3.4 times), 'Raduga' (3.2 times), 'Krymskaya Krasnaya' (3.1 times) and sample N37-24 (3.0 times). For several samples (G2168 and M215), this increase was small (1.4-1.6 times). In the fifth subculture the multiplication index decreased, but in most cultivars and samples it was higher than in the first subculture. The influence of the genotype on the efficiency of micropropagation of essential oil rose was revealed. At longterm subcultivation, the best morphogenetic potential was noted for cultivar 'Raduga' and samples G2168, N37-2, in which the multiplication index reached 14.2, 14.4 and 11.8, respectively. The minimal ability to propagation in vitro was in samples M215 and N138; their multiplication index did not exceed 1.8 and 4.0, respectively. The results indicate the effectiveness of long-term micropropagation of cultivars and breeding samples of essential oil rose (for at least 5 subcultures) without loss of microshoots quality.

\section{References}

1. Khosh-Khui M 2014 Int. J. Hortic. Sci. Technol. 1(1) 1-20

2. Ginova A, Tsvetkov I and Kondakova V 2012 Bulg. J. Agric. Sci. 18(4) 545-556

3. Kumar A and Palni L M S 2015 J. Hortic. Sci. Biotech. 78(6) 786-792 doi:10.1080/14620316.2003.11511700

4. Pashtetskii V S, Nevkrytaya N V, Mishnev A V and Nazarenko L G 2017 Essential Oil Industry in the Crimea. Yesterday, Today, Tomorrow (Simferopol: Arial) pp 66-84

5. Allahverdi Mamaghani B, Ghorbanli M, Assareh M H and Ghamari Zare A 2010 Iran. J. Plant Physiol. 1(2) 85-94

6. Nikbakht A, Kafi M, Mirmasoumi M and Babalar M 2005 Int. J. Agric. Biol. 7(4) 535538

7. Bosh A, Moieni A, Dehghani H and Movahedi Z 2016 J. Plant Physiol. Breed. 6(2) 918

8. Mirzaei S, Zare A G and Jafary S 2019 International Journal of Environment, Agriculture and Biotechnology (IJEAB) 4(5) 1407-13 doi:10.22161/ijeab.45.19

9. Noodezh H M, Moieni A and Baghizadeh A 2012 In Vitro Cell. Dev. Biol. Plant 48(6) 530-538 doi: $10.1007 / \mathrm{s} 11627-012-9454-\mathrm{z}$

10. Mitrofanova I V, Mitrofanova OV, Brailko VA and Lesnikova-Sedoshenko N P 2015 Proc. Univ. Appl. Chem. Bbiotechnol. 2(13) 37-48

11. Jabbarzadeh $\mathrm{Z}$ and Khosh-Khui M 2005 Sci. Hort. 105(4) 475-482 doi: 10.1016/j.scienta.2005.02.014

12. Badzhelova V and Bozhanova V 2018 Rastenievadni nauki 55(6) 37-44

13. Salekjalali M American-Eurasian J. Agric. And Environ. Sci. 12(7) 960-966 doi:10.5829/idosi.aejaes.2012.12.07.1799

14. Ginova A. and Kondakova V 2013 Bulg. J. Agric. Sci. 19 1198-1203

15. Omidi M, Yadollahi A and Malihe E 2016 Biological Forum - An International Journal (BFIJ) 8(1) 135-145

16. Kshirsagar K and Braganza V J 2012 South Asian Journal of Experimental Biology (SAJEB) 2(4) 184-189

17. Kumar A, Sood A, Palni U, Gupta A and Palni L M 2001 J. Hortic. Sci. Biotech. 76(1) 30-34

18. Yegorova N A and Stavtseva I V 2016 Bulletin of Udmurt University. Series Biology. Earth Sciences 26(2) 45-52 
19. Senapati S K and Rout G R 2008 Hort. Sci. (Prague) 35(1) 27-34

20. Yegorova N A, Mitrofanova I V, Brailko V A, Grebennikova O A, Paliy A E and Stavtseva I V 2019 Russ. J. Plant Physiol. 66(2) 326-334 doi: $10.1134 / \mathrm{S} 1021443719010060$

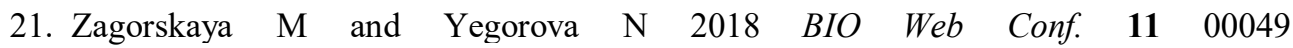
doi: 10.1051/bioconf/20181100049

22. Yegorova N A and Yakimova O V 2019 Tomsk State University Journal of Biology (BIO TSU) 47 22-39 doi:10.17223/19988591/47/2

23. Vardja R and Vardja T 2001 Proc. Estonian Acad. Sci. Biol. Ecol. 50(1) 22-32

24. Yadav K and Singh N 2012 Iran. J. Biotechnol. 10(3) 161-167

25. Mohamed G R A, Khusnetdinova L Z and Timofeeva O A Asian J. Plant Sci. Res. 8(5) $1-11$

26. Radha R K, Varghese A M and Seeni S 2013 Sci. Asia 39 219-229 doi:10.2306/scienceasia1513-1874.2013.39.219

27. Vujović T, Ružić Dj and Cerović R 2012 Hort. Sci. (Prague) 39 101-107 